\title{
RESEARCH OF TOOTHED BELT TRANSMISSION WITH ARCHED TEETH
}

\author{
Oleg KROL, Volodymyr SOKOLOV \\ Volodymyr Dahl East Ukrainian National University, Department of Machinery Engineering and Applied \\ Mechanics, 59-a Central pr., Severodonetsk, 93400, Ukraine \\ e-mail: krolos.snu.edu@gmail.com
}

\begin{abstract}
The presented work is devoted to the search for a new design of the toothed belt transmission for the drive of metal-cutting machines. The main constructive solution underlying the modernization of the existing transmission is associated with a change in the shape of the toothed belt teeth pulley to increase durability. The authors propose to consider the effectiveness of the design decisions made through the prism of increasing the load capacity of the toothed belt associated with an increase in the contact length of the arched shape teeth and the reduction of additional friction losses of the belt flanks along the flanges at the pulleys end surfaces designed to restrain the belt from transverse sliding from the pulleys. The authors conclude that a comparative analysis of typical and modernized structures must be based on the postulates of contact areas belt and pulley equality and the belt cross-sectional areas. The procedure of three-dimensional modelling of elements and assemblies of a toothed belt drive for a drill-milling-boring machine type is considered as a basis for a comprehensive further study of their effectiveness and efficiency. Particular attention is paid to the parameterization toolkit in CAD "APM WinMachine", the construction of algorithms and programs for creating unified toothed belt transmission components taking into account the variable design. The conceptual moment of the study is the proposed procedure for creating a specialized database of parametric design solutions.
\end{abstract}

Keywords: toothed belt transmission, machine tool drive, tooth arches form, 3D model, parameterization toolkit

\section{INTRODUCTION}

Drives of the main movement of $\mathrm{CNC}$ machine tools use mechanisms with a DC motor and a thyristor voltage converter. Drives of this design require dual-zone regulation. So, for a $2 \mathrm{P}$ series DC motor, the spindle speed control range is only $1 \ldots 4$ from the rated angular frequency of revolution $\omega_{r}$ in the downward direction. According to technological requirements, this range needs to be increased, which is carried out by introducing an additional gearbox and a belt transmission. There are several benefits specific to different types of belt transmissions. First of all, it is low noise, smoothness, and compensation of overloads in the start-up mode (which is typical for $\mathrm{V}$-belt and multi-V-gear drives). Besides, it is necessary to maintain gear ratios when changing the external load and provide a sufficiently high efficiency, which is typical for toothed belt transmissions (TBT). A large range of metal-cutting equipment determines the variety of types and designs of belt drives. This leads to an increase in time spent on designing workable transmission options. One way to increase the productivity of the design process is to use the parameterization mechanism [1]. The obtained parametric transmission models will streamline the design process in a $2 \mathrm{D}$ editor and modelling in a $3 \mathrm{D}$ editor.
The effectiveness in this regard is shown by the APM WinMachine system [2-4].

In modern computer-aided design (CAD) systems, a parameterization toolkit is implemented to reduce design time and improve the quality of design decisions made [5]. In CAD systems of the "middle" and "heavy" class, the presence of a parametric model is embedded in the functioning mechanism of CAD systems. The existence of the object parametric description is the basis for the entire design process [6]. The process of parametric modelling involves using the parameters of the model elements and the relationships between these parameters, which allows you to efficiently generate various versions of the designed objects using parameter variations or geometric relationships. Unlike traditional 2D and 3D design, the use of parameterization tools allows you to create a mathematical model of a belt drive structure with parameters that, when variated, change the configuration of the structure, the relative positions of parts in the assembly, etc. The original approach for parametric optimization was proposed for the fixture design of lever-type parts in the research study [7]. The accuracy of units functioned on gearbased mechanisms was investigated in the research study [8]. It was proved that the locating accuracy of gear mechanisms is sufficient for precision locating of shafts in V-blocks. 
The problems of constructing parametric models are associated with the lack of clear relationships and interrelations of the shapes and sizes of belt drive elements with kinematic and power input characteristics. This is well illustrated by the example of TBT-analysis according to the load capacity criterion.

\section{LITERATURE REVIEW}

The Patent of USA [9] discloses a TBT comprising a belt whose teeth have a convex profile and pulleys, the tooth cavities of which are concave and the heads are convex. The height of the belt teeth is greater than the depth of the pulley teeth cavity. The gap-free engagement is carried out as a result of the compression of the belt teeth in height. The disadvantages of this transmission design are the deformation of the belt teeth when they engage, the presence of flanges at the pulleys end surfaces, which leads to additional power losses on friction, as well as the increased effect of the accuracy of manufacturing the tooth profile on the load distribution along with the height of the teeth. Resizing the belt should be monitored online. In this regard, a promising device for measuring the thickness of the conveyor belt and for assessing changes in the transverse and longitudinal profile of the belt [10]. Measurements are carried out continuously along the axis of the belt and are controlled by an application called DiagBeltSonic, specially designed for this purpose. The application allows the designer to determine some basic information about the conveyor belt device before the start of testing. The measurement results show the cross-section of the belt along the entire length, as well as the longitudinal and transverse profiles of the tested belt.

It is also important to control the efforts arising in the belt drive. In work [11] developed algorithms for calculating the primary resistance to movement of the conveyor belt, taking into account the parameters of the belt, as well as the design and operational parameters of the conveyor. This identification of energy characteristics becomes more reliable due to the introduction of IT systems, the collection of complex data (technical, operational, diagnostic) [11]. Automated data processing provides a reliable assessment of the state of conveyor elements and additionally, supported by the results of simulation calculations. In work [12] considered the phenomenon of increasing the pitch of the toothed belt and, as a result of its lengthening, which occurs during operation and which remains after unloading the belt. The author emphasizes that the greatest amount of movement and power is transmitted by the form, while only a small amount is transmitted by friction. The mechanisms of this phenomenon, the main factor is the plastic deformation of the belt of about $70 \%$ are revealed. An analysis also of another factor related to rolling along the side surface (flank) of the belt was made. The classification of the main movements of the toothed belt (impact, sliding, rolling) within the framework of tribomechanical systems is given. Of interest is the phenomenon of rolling during linear contact of the belt tooth and the side surface of the pulley tooth. During the engagement, interference occurs when the tooth of the belt cuts into the side surface of the pulley tooth. Unlike gearing, this phenomenon leads to a sharp increase in the deformation of the belt, but with a simultaneous increase in the contact surface of the belt with the pulley [12]. The authors point out the importance of considering the frictional force on the sides of the belt and pulley. Besides, one cannot ignore the frictional forces on the surfaces of the belt flanges and, as a consequence, also change the belt pitch. These processes in combination lead to disruption of the toothed belt, which is expressed in a change in load distribution, a decrease in load capacity, and uneven operation. There is a need for additional belt tension, which directly affects the durability of the toothed belt drive [12].

However, in the above works, insufficient attention is paid to improving the design (shape) of the toothed belt and its effect on tractive characteristics and durability.

The purpose of this work is to improve a toothed belt transmission design by finding a rational geometry of the belt teeth and the corresponding geometry of the pulleys, as a result of which it is expected to increase the load capacity of the transmission by the toothed belt.

\section{3D MODELING OF MACHINING CENTER DRIVES WITH TOOTHED BELT TRANSMISSION}

A characteristic representative of $\mathrm{CNC}$ machines with an extended control range is a specialized multioperational machine model SF68VF4H [13-15]. This machine has a cantilever layout with longitudinally movable cross slide, along which the angular and rotary tables are transversely moved, as well as a horizontally movable spindle headstock. In the environment of the integrated computer-aided design system KOMPAS-3D [16-18], a complex of threedimensional models of the design of the drive of the main movement for this multioperational machine has been developed (Fig. 1). The headstock of the machine (Fig. 1) consists of cast iron housing, spindle block with a mechanism for automatic tool clamping, a camshaft transmitting rotation to a horizontal or vertical spindle using an automatic gear shifter; two-speed gearbox with a toothed belt transmission driving movement from the engine. This set of mechanisms ensures the normal functioning of the headstock from the CNC device. CAD KOMPAS today is a multi-functional 3DCAD system with its mathematical core $[19,20]$. 


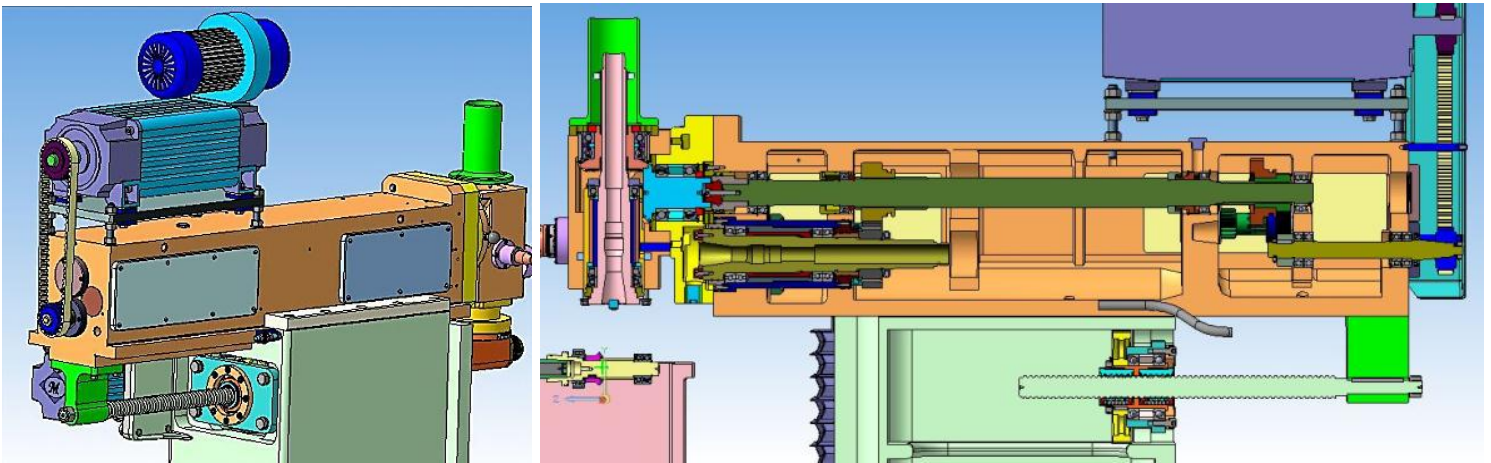

a)

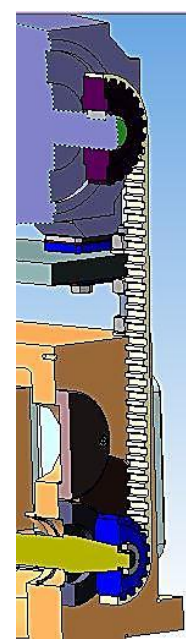

c)

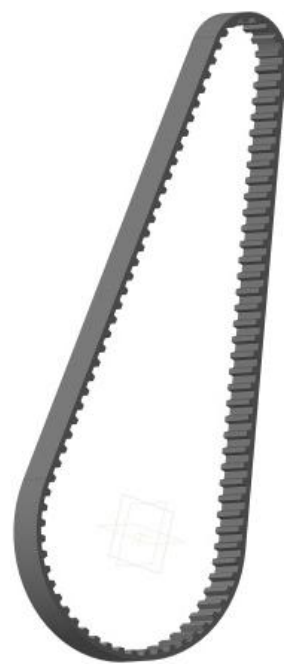

d)

b)

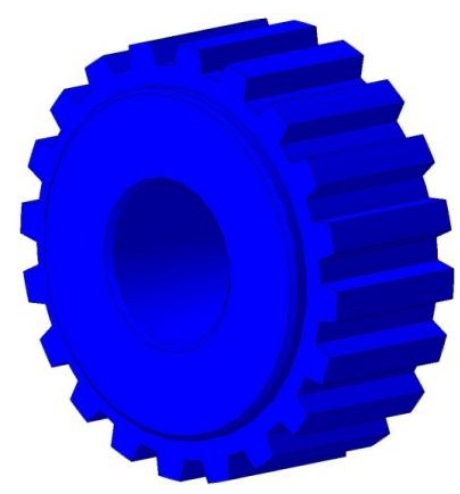

e)

Fig. 1. 3D models of the main movement drive for the multioperational machine

The pulleys used in machine tools in their form in many cases do not differ from the pulleys common in other machines. A variety of nomenclature used in pulley drives, on the one hand, and the availability of normative documentation regulating the shapes and sizes of their structures, makes the use of the parameterization mechanism promising [25-27].

A comprehensive engineering analysis of the stressstrain state of the machine spindle is possible using the FEM module [21-24], equipped with a finite element mesh generator included in the CAE-library, which implements the solution of engineering problems by the finite element method.

To improve the design processes, it is advisable to use a parametric transmission model with a toothed belt for various design variations. On this basis, it is possible to carry out a comprehensive study of the stress-strain state characteristics of the pulley and belt teeth, choose the best transmission design, characterized by a uniform load distribution and a decrease in its greatest value $[10,11,20]$.

To create a parametric model of gear transmission it is advisable to use the CAD/CAE APM WinMachine which includes the APM Graph module [27, 28]. To obtain a parametric model, you just need to match the mathematical formulas and/or logical expressions (if required) with the numerical parameters.

A feature of this graphic editor is the presence of an evolving parameterized database [29, 30], which involves the creation of our authoring sections focused on certain classes of machine parts and machine tool complexes.

\section{MODIFICATION OF TOOTHED BELT TRANSMISSION}

When TBT designing, which are widely used in the drives of modern machines, one of the significant factors is the distribution of the transmitted load between the teeth of the belt engagement with the pulleys. Toothed belts have the largest number of design variations compared to flat, round, and V-belts. They have several advantages, providing a smoother transmission, eliminating the possibility of slippage relative to the pulley; however, they create a not so high load on the shafts and bearings from the tension of the belt transmission and provide the highest efficiency.

When TBT designing, which are widely used in the drives of modern machines, one of the significant factors is the distribution of the transmitted load between the teeth of the belt engagement with the pulleys. Toothed belts have the largest number of design variations compared to flat, round, and V-belts. They have several advantages, 
providing a smoother transmission, eliminating the possibility of slippage relative to the pulley; however, they create a not so high load on the shafts and bearings from the tension of the belt transmission and provide the highest efficiency.

The ultimate goals of any modernization of friction belt drives are to increase the traction ability of belts and their durability. This led to the creation of $\mathrm{V}$-belts, and then poly-V-belts. One of the reasons for the insufficient durability of V-belts and poly-Vbelts is the significant bending stress caused by the relatively large thickness of these belts. Considering a TBT as an alternative, it is necessary to build on the most common TBT, which contains a belt with teeth of a trapezoidal profile in normal section and pulleys, whose teeth also have a trapezoidal profile in normal section [31].

One of the significant drawbacks of this transmission is the low load capacity of the toothed belt and the additional friction losses of the side faces of the belt along the flanges at the end surfaces of the pulleys designed to restrain the belt from transverse slipping from the pulleys.

To reduce the effect of these negative factors in this work is achieved by the fact that in the transmission with a toothed belt containing a belt and pulleys with teeth of a trapezoidal profile in a normal section, the shape of their teeth changes in the longitudinal direction and is presented in the form of arches [32]. In this case, the teeth of the belt located on the inner surface in the cross-section have a convex contour, which is outlined by an arc of a circle with a radius, and the toothed rims on the pulleys in a cross-section have concave contours, also outlined by an arc of a circle. In a CAD KOMPAS-3D in the specialized application "Shafts and mechanical gears-3D" a three-dimensional model of the upgraded TBTar was developed (Fig. 2).

When TBT designing, which are widely used in the drives of modern machines, one of the significant factors is the distribution of the transmitted load between the teeth of the belt engagement with the pulleys. Toothed belts have the largest number of design variations compared to flat, round, and V-belts. They have several advantages, providing a smoother transmission, eliminating the possibility of slippage relative to the pulley; however, they create a not so high load on the shafts and bearings from the tension of the belt transmission and provide the highest efficiency.

The ultimate goals of any modernization of friction belt drives are to increase the traction ability of belts and their durability. This led to the creation of $\mathrm{V}$-belts, and then poly-V-belts. One of the reasons for the insufficient durability of V-belts and poly- $\mathrm{V}$ belts is the significant bending stress caused by the relatively large thickness of these belts. Considering a TBT as an alternative, it is necessary to build on the most common TBT, which contains a belt with teeth of a trapezoidal profile in normal section and pulleys, whose teeth also have a trapezoidal profile in normal section [31].

One of the significant drawbacks of this transmission is the low load capacity of the toothed belt and the additional friction losses of the side faces of the belt along the flanges at the end surfaces of the pulleys designed to restrain the belt from transverse slipping from the pulleys.

To reduce the effect of these negative factors in this work is achieved by the fact that in the transmission with a toothed belt containing a belt and pulleys with teeth of a trapezoidal profile in a normal section, the shape of their teeth changes in the longitudinal direction and is presented in the form of arches [32]. In this case, the teeth of the belt located on the inner surface in the cross-section have a convex contour, which is outlined by an arc of a circle with a radius, and the toothed rims on the pulleys in a cross-section have concave contours, also outlined by an arc of a circle. In a CAD KOMPAS-3D in the specialized application "Shafts and mechanical gears-3D" a three-dimensional model of the upgraded TBTar was developed (Fig. 2).

TBTar operates as follows. When the belt 1 runs onto the pulley 2 , the longitudinally convex teeth of the belt 1 enter the concave cavities of the pulley 2 . As a result, the driving pulley 2 set in motion the belt 1 , which, in turn, transmits the movement to the driven toothed belt pulley.

Consider the geometry of such an upgraded engagement (Fig. 3).

Here in Fig. 3, a fragment of a toothed belt in a normal section is shown, which is characterized by the following parameters: $s$ - width of the teeth tips; $P$ - pitch between teeth; $H$ - thickness of the layer where the cord threads are located (they are not shown in Fig. 2, a); $\gamma$ - the angle of the tooth profile.

The cross-section contour of the modified toothed belt is outlined by an arch turning into a rectangle, that is, the cross-section is a combination of a circle segment with a radius $R$ and a central angle $\beta$ with a rectangle of size $H \times b$, Fig. 1 . The basis for the modification of toothed belts are 3 conditions:

1) the equality of the contact area with the belt pulleys of traditional design OST 38 05114-76 [19] and modified [20];

2 ) the equality of the arch width $s_{a}$, where the cord of the modified belt is located [20], Fig. 1, and a section width of a standard V-belt $w$;

3 ) the equality of the cross-sectional areas of standard and modified belts.

The radius $R$ is calculated by the following ratio:

$$
R=\frac{\sqrt{b^{2}+36 \cdot h^{2}}}{4 \cdot \sin (\beta / 2)},
$$

where $b$ - the width of the belt, $\mathrm{mm} ; h$ - the height of the belt teeth, mm; $\beta$ (bet) - the angle of half the 

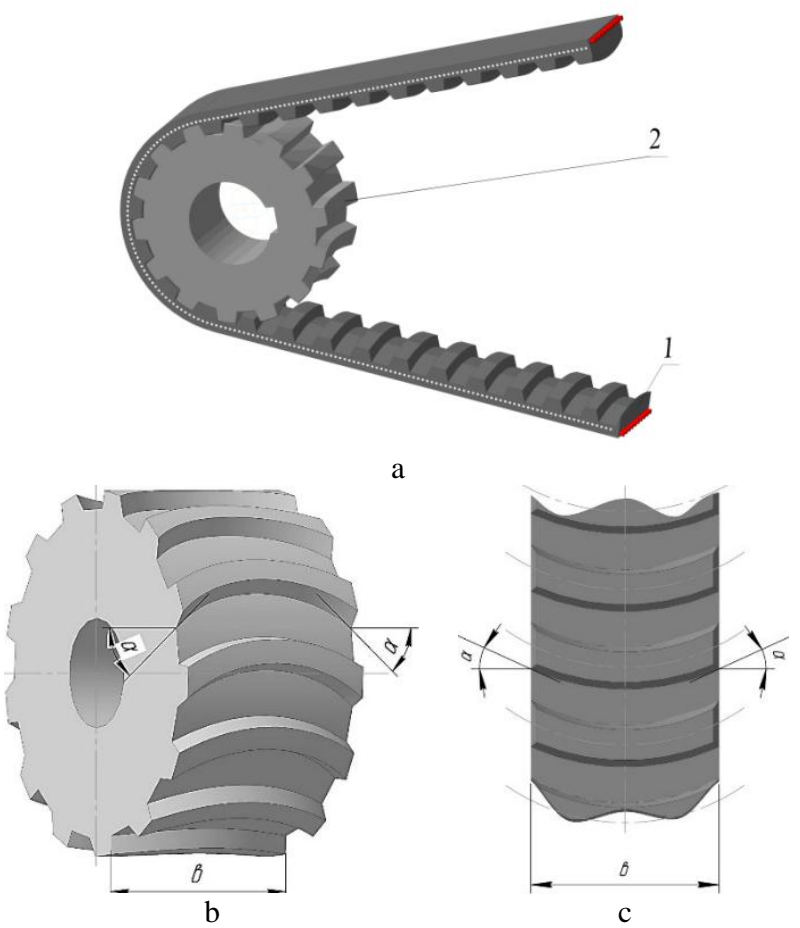

Fig. 2. The three-dimensional model of a TBTar: a - transmission assembly; $\mathrm{b}$ - toothed pulley; $\mathrm{c}$ - teeth of TBTar in the longitudinal direction

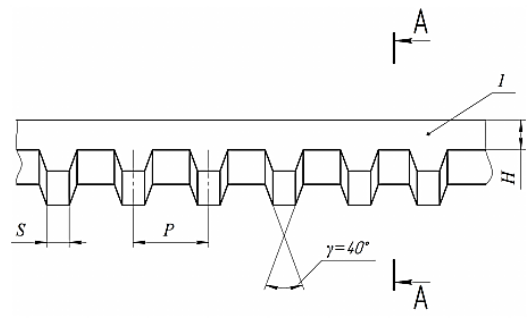

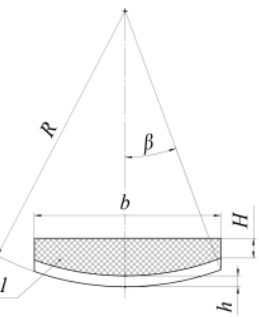

Fig. 3. The geometry of the TBTar-elements: $a$ - toothed belt; $b$ - section of the belt in the longitudinal direction

sector whose arc defines the convex belt tooth surface in cross-section. The value of the angle $\beta$ is the root of the transcendental equation:

$$
\begin{aligned}
& 2 \cdot b \cdot \operatorname{ctg} \beta \cdot \sin (\beta / 2)+12 \cdot h \cdot \sin (\beta / 2)- \\
& \left.-\sqrt{b^{2}+36 \cdot h^{2}}\right)=0 .
\end{aligned}
$$

Due to the convex shape of the belt inner surface where the teeth are located, and the concave shape of the toothed rims on the pulleys, firstly, the length of the teeth increases, which leads to an increase in the load-carrying capacity of the toothed belt. Secondly, the belt is self-centred on the pulleys, as a result of which there is no need for flanges at the end surfaces of the pulleys. These factors, in turn, reduce friction losses between the toothed flank of the belt and pulley and increase belt durability.

With this transmission design, the calculated circumferential force $F_{t}(\mathrm{~N})$, which is transmitted by the belt, is determined by the criterion of the tractive ability of the belt:

$$
F_{t}=d_{t h} \cdot\left(F_{t s}-q \cdot V^{2}\right) \cdot \arcsin \left(b / d_{t h}\right),
$$

where $b$ - width of the timing belt $(\mathrm{mm}) ; F_{t s}$ calculated specific circumferential force $(\mathrm{N} / \mathrm{mm}) ; q$ - linear density of $1 \mathrm{~m}$ of a belt $1 \mathrm{~mm}$ wide $\left(\mathrm{kg} /(\mathrm{m} \cdot \mathrm{mm}) ; V\right.$ - belt speed $(\mathrm{m} / \mathrm{s}) ; d_{t h}$ - diameter of the tool head.

For the angle of inclination at the pulley end surfaces $\alpha=(\pi / 6) \ldots(\pi / 4)$, the calculated circular force, ceteris paribus, is $5 \ldots 11 \%$ more than that of the prototype belt. The shape and ratio between the proposed parameters of the teeth profiles of the belt and pulleys and the standard design are the same.

\section{RESULTS AND DISCUSSION}

For a wide range of TBT-pulleys, calculation forms that are used in the "Variable window" of the APM Graph module have been developed (Table 1). In the "Command window", a sequence of assigning graphic primitives is realized that implements the 
construction of the image of TBTar-elements. So, the construction of the trapezoidal tooth shape is carried out by setting the length of the segments $L$ and the angle of inclination $\alpha$. Table 1 shows the construction of the groove side surface (flank) length $L_{g}$ with the groove profile angle $\beta_{g}$.

In the process of constructing the belt structure, the "Rectangular array" command is used, in which it is assigned the number of rows: $x=1$; and the number of columns $z_{0}$ equal to the number of teeth engaged with a smaller pulley. The number of the latter depends on the number of teeth on the smaller pulley $z_{p 1}$ and the angle of the belt circumference $\alpha_{1}$ of the smaller pulley.

To create a TBTar-parametric model it is advisable to use the of the belt cord turns is determined by the pitch $P_{b}$ and number of turns $n_{1}$.

To account for the TBTar variant, additional commands for calculating the radius of the arch profile and the corresponding sector angle ((bet) in the cross-section are entered into the "Variable window" (Fig. 4).

To improve the design processes, it is advisable to use a parametric transmission model with a toothed belt for various design variations, based on which it is possible to carry out a characteristics comprehensive study of the stress-strain state of the pulley and belt teeth, choose the best transmission design, characterized by a uniform load distribution and a decrease in its greatest value [12].

The APM WinMachine system includes the APM Base module - a database creation module [30]. The main advantage of the proposed approach to creating a user database is the use of parametric models as objects obtained in the parameterized drawing and graphic module APM Graph. This makes it possible to add entire classes of data, using a small set of models for a wide range of designed objects. An effective tool is the concept of a group of models when combined, their common summary table of geometric parameters is formed. This module allows the developer to create sections of specialized databases. This article proposes a specialized database of TBT for multi-operational machine drives (Fig. 5).

Thus, the design process based on our database with parametric models allows us to use it to create drawings and other design documentation, as well as for the source of additional data used in the calculation modules. Based on the developed database, it is possible to create a user archive where the most commonly used models and data will be collected. So the creation of a TBT-class can be reduced to adding a small set of models corresponding to one or another type and section of a belt and toothed pulley.

Table 1

\begin{tabular}{|c|l||c|}
\hline \multicolumn{1}{|c|}{ Creating a tooth shape } & Creating a rectangular array of teeth & Create a rectangular array of ropes \\
\hline \hline$L_{g}=\frac{h_{1}}{\cos \left(\operatorname{rad}\left(2 \beta_{g}\right)\right.} ; \alpha=90-\beta_{g}$. & Rows: $x=1 ;$ & Rows: $x=1 ; P_{b}=\frac{b}{n_{1}-1} ;$ \\
Column: $z_{0}=z_{p 1} \cdot \frac{\alpha_{1}}{360}$. & Column: $n_{1} ; \alpha=180$. \\
\hline
\end{tabular}

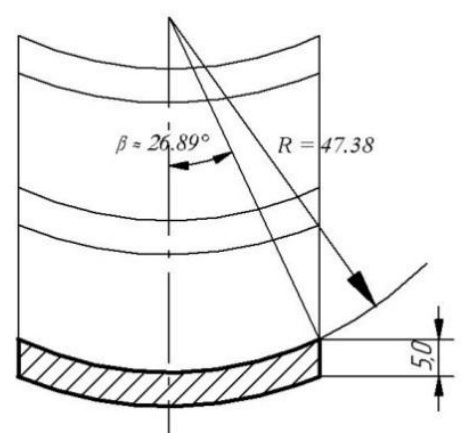

\begin{tabular}{|c|c|c|c|}
\hline $\mathrm{t} 1=-2=-2=$ & $.5^{\times}(\mathrm{m}>1.58 \mathrm{~m}<=2.5)+.7^{\times}(\mathrm{m}>2$. & 1.5 & Top radius $=$ \\
\hline 12 & $.5^{\times}(\mathrm{m}>1.58 \mathrm{~m}<=2.5)+1^{\times}(\mathrm{m}>2 !$ & 2 & Cavity radius \\
\hline B & $b+m$ & 45 & Pulley tooth length \\
\hline dn & $24^{x}(\mathrm{~N}\rangle=18 \mathrm{~N}\langle=2.5)+28^{x}(\mathrm{~N}\rangle \hat{\mathrm{L}}$ & 24 & Pulley bore diameter \\
\hline tp & M_Pl'm & 15.7079632679 & Design belt pitch along the midline of the groove \\
\hline & tp. $\left(2^{x} \mathrm{M}_{-} \mathrm{Pl} \times(\right.$ del+h1/2) $) / 21$ & 14.6433124242 & Circumferential pitch along the midline of the tee \\
\hline gam & $\left.50^{\circ}(m)=1.58 \mathrm{~m}<=2.5\right)+40^{\times}(\mathrm{m}$ & 40 & Cavity angle (tooth profile angle) \\
\hline s1. & $2.23^{*}(m>1.58 \mathrm{~m}<=2.5)+3.42^{x}$ & 5.7 & Belt tooth thickness iL \\
\hline f: & $.8^{\prime \prime}\left(\mathrm{m}>1.58 \mathrm{~m}\langle=2.5)+1.2^{\mathrm{N}}(\mathrm{m}\rangle\right.$ & 1.5 & Side clearance between pulley teeth and belt \\
\hline ssk $=$ & $t \cdot\left(s 1+1.1^{m} f\right) \Rightarrow \quad \Rightarrow 0^{\circ}$ & 7.2933124242 & Pulley tooth thickness at medium height \\
\hline$\$ 2 \square$ & ssk-h1 $\tan (\operatorname{rad}(\operatorname{gam} / 2))$ & 5.65544637 & Pulley Tooth Thickness at Apex \\
\hline$\$ 4$ & $s 2+2 \times 1 \times \tan (\operatorname{rad}(\operatorname{gam} / 2))$ & 8.9311784784 & Pulley tooth thickness at the base \\
\hline$\$ 5$ & $(t-\$ 4) / 2$ & 2.8560669729 & Half Pulley Cavity Width \\
\hline bet? & asin(b/da1) $180 / M_{-} P$ I d al & 26.8916903276 & Half sector angle \\
\hline$R=$ & $\operatorname{sqr}\left(b^{* * 2} 2+36^{*} 1^{* * 2}\right) /\left(4.0^{*} \sin 1\right.$ & $51.8863198015=$ & Radius of convex contour in cross section \\
\hline
\end{tabular}

Fig. 4. Parametric model (fragment) of TBTar: a - arch profile of the tooth; b - "Variable window" of the parametric model 


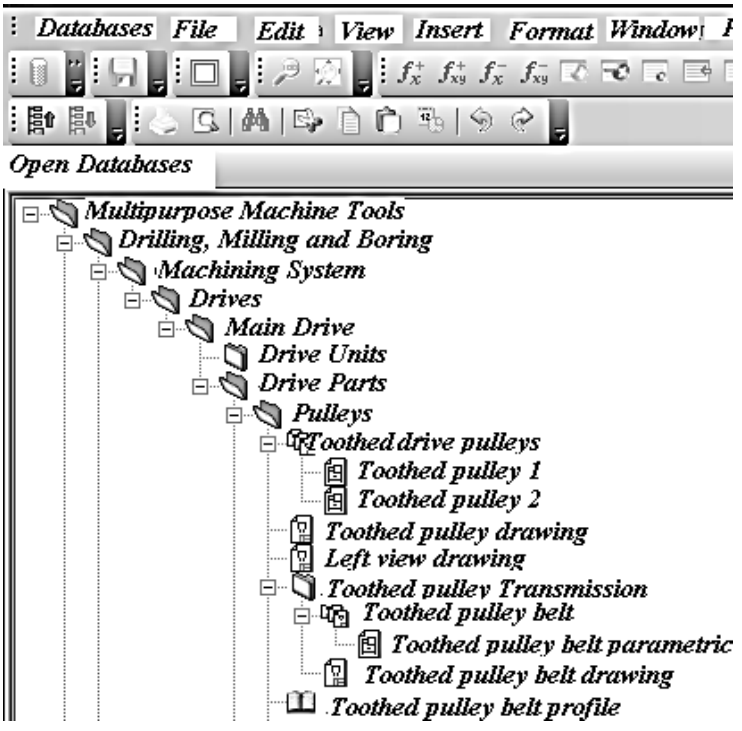

Fig. 5. Specialized TBT Database

\section{CONCLUSION}

The design of the TBTar for the multioperational machine of a drilling-milling-boring type has been carried out. 3D models of the machine tool gearbox with a toothed belt drive in CAD KOMPAS-3D were constructed using the application program "Shafts and Mechanical Transmissions-3D". A modernized TBTar- construction with arched teeth in the longitudinal direction has been developed. This design is based on the patent solution obtained by the authors. The analysis of the effectiveness of the new design TBTar is carried out and the main structural dimensions of the transmission with increased tractive ability are determined. An algorithm has been generated and graphical and calculation forms have been built, which are necessary for creating parametric models of TBTar in the drawing-graphic editor of APM Graph. A fragment of a parametrized database is constructed in the APM Base module. The TBTar design procedure has been implemented using the appropriate database, which significantly reduces the design process of a whole TBT-class. The results obtained in this paper allow the construction of parametric models of various design variations of transmissions with a modernized toothed belt of a trapezoidal profile. There is an opportunity to effectively simulate the process of more uniform load distribution along with the belt teeth and increase the reliability of the operation of toothed belt drives.

As prospects for further development, the formation of links with the CAM-module for technological preparation of production of modernized toothed belt drive structures based on the constructed 3D models is considered. Another area of development is the improvement of the parameterization mechanism and the creation of a database for various types of belt drives.

\section{REFERENCES}

1. Kotliar A, Basova Y, Ivanov V, Murzabulatova O, Vasyltsova S, Litvynenko M, Zinchenko O. Ensuring the economic efficiency of enterprises by multicriteria selection of the optimal manufacturing process. Management and production engineering review. 2020; 11(1):52-61. http://dx.doi.org/10.24425/mper.2020.132943.

2. Zamriy AA. Practical training course CAD/CAE APM WinMachine. Teaching aid. Moscow: APM Publishing house. 2007. Russian.

3. Shelofast VV. Fundamentals of machine design. Moscow: APM Publishing house, 2005. Russian.

4. Krol O, Sokolov V. Parametric Modeling of Gear Cutting Tools. In: Gapiński B., Szostak M., Ivanov V. (eds) Advances in Manufacturing II. Manufacturing. 2019. Lecture Notes in Mechanical Engineering. Springer, Cham 2019; 4: 3-11. https://doi.org/10.1007/978-3-030-16943-5_1

5. Dobrotvorskiy S, Basova Y, Dobrovolska L, Sokol Y, Kazantsev N. Big Challenges of Small Manufacturing Enterprises in Industry 4.0. In: Ivanov V. et al. (eds) Advances in Design, Simulation and Manufacturing III. DSMIE 2020. Lecture Notes in Mechanical Engineering. Springer, Cham 2020; 1: 118-127. https://doi.org/10.1007/978-3-030-507947_12.

6. Krol O, Sokolov V. Parametric Modeling of Transverse Layout for Machine Tool Gearboxes. In: Gapiński B., Szostak M., Ivanov V. (eds) Advances in Manufacturing II. Manufacturing. 2019. Lecture Notes in Mechanical Engineering. Springer, Cham 2019; 4: 122-130. https://doi.org/10.1007/978-3-03016943-5_11.

7. Ivanov V, Dehtiarov I, Pavlenko I, Liaposhchenko O, Zaloga V. Parametric optimization of fixtures for multiaxis machining of parts. In: Hamrol A., Kujawińska A., Barraza M. (eds) Advances in Manufacturing II. Manufacturing. 2019. Lecture Notes in Mechanical Engineering. Springer, Cham 2019; 2: 335-347. https://doi.org/10.1007/978-3-03018789-7 28.

8. Karpus VE, Ivanov VA. Locating accuracy of shafts in V-blocks. Russian Engineering Research 2012; 32(2):144-150.

https://doi.org/10.3103/S1068798X1202013X.

9. Patent of US 21337485, cl. 73-229. 21.07.1977.

10. Błażej B, Jurdziak L, Kirjanow A, Kozłowski T. A device for measuring conveyor belt thickness and for evaluating the changes in belt transverse and longitudinal profile. Diagnostyka. 2017;18(4):97-102.

11. Gładysiewicz L, Kawalec W, Krol R. Selection of carry idlers spacing of belt conveyor taking into account random stream of transported bulk material. Eksploatacja i Niezawodnosc - Maintenance and Reliability. 2016;18(1):32-37. http://dx.doi.org/10.17531/ein.2016.1.5

12. Stojanović B., Miloradović N., Marjanović N., Blagojević M., Ivanović L. Length Variation of Toothed Belt During Exploitation. Strojniški vestnik. Journal of Mechanical Engineering 2011; 57(9): 648654. https://doi.org/10.5545/sv-jme.2010.062

13. Avramova TM, Bushuev VV, Gilova LY. Handbook on metal-cutting machine tools. Moscow: Mechanical Engineering, 2012. Russian.

14. Sokolov V, Krol O, Stepanova O. Choice of Correcting Link for Electrohydraulic Servo Drive of 
Technological Equipment. In: Ivanov V. et al. (eds) Advances in Design, Simulation and Manufacturing II. DSMIE 2019. Lecture Notes in Mechanical Engineering. Springer, Cham. 2020; 702-710. https://doi.org/10.1007/978-3-030-22365-6_70

15. Krol O, Sokolov V. 3D modelling of angular spindle's head for machining centre. J. Phys.: Conf. Ser. VSPID-2018. 2019; 1278: 012002. https://doi.org/10.1088/1742-6596/1278/1/012002

16. Ganin N. Three dimensional modelling in KOMPAS3D. Moscow: DMK Publishing house, 2012. Russian.

17. Fomin E.P. Using the parametric capabilities of KOMPAS-3D. CAD and graphics. 2007; 10: 70-74.

18. Sokolov V, Krol O, Stepanova O. Nonlinear simulation of electrohydraulic technological equipment/ J. Physics: Conf. Series. VSPID-2018 2019; 1278: 012003. https://doi.org/10.1088/1742$6596 / 1278 / 1 / 012003$

19. Kamnev A. C3D labs represent the C3D Toolkit. Topical technologies for developers of engineering software. Isicad 2017; 154: 12-18.

20. Pritykin FN, Shmulenkova EE. The main elements of CAD metal-cutting tools when using parametric 3D modelling. Omsk Scientific Herald 2012; 1(107): 278-282. Russian.

21. Yakovenko I, Permyakov A, Prihodko O, Basova Y, Ivanova M. Structural optimization of technological layout of modular machine tools. In Tonkonogyi V. et al. (eds). Advanced Manufacturing Processes. InterPartner-2019. Lecture Notes in Mechanical Engineering. Springer. 2020; 352-363. https://doi.org/10.1007/978-3-030-40724-7_36

22. Ivanov V. Process-oriented approach to fixture design. In Ivanov V. et al. (eds) Advances in Design, Simulation and Manufacturing. DSMIE-2018. Lecture Notes in Mechanical Engineering. Springer. Cham 2019; 42-50. https://doi.org/10.1007/978-3319-93587-4_5

23. Yakovenko I, Permyakov A, Naboka O, Prihodko O, Havryliuk Y. Parametric Optimization of Technological Layout of Modular Machine Tools. In: Ivanov V. et al. (eds) Advances in Design, Simulation and Manufacturing III. DSMIE 2020. Lecture Notes in Mechanical Engineering. Springer, Cham. 2020; 1: 85-93. https://doi.org/10.1007/978-3030-50794-7 9

24. Magomedov A, Alechin A. Integrated finite element analysis in KOMPAS-3D. CAD/CAM/CAE observer 2010; 8(60): 1-5.

25. Girschtick J. Introducing parametric modelling 2.0. Isicad 2018; 162: 8-14.

26. Shelofast VV, Chugunova TB. Fundamentals of machine design. Examples of problem-solving. Moscow: APM Publishing house, 2004. Russian

27. Rozinsky S, Shanin D, Grigoriev S. Parametric capabilities of the graphic module APM Graph of the APM WinMachine system. CAD and graphics 2001; 11: $17-40$
28. Kondrashova SG, Khamidulina DA, Lashkov VA. Engineering design of mechanisms using the APM WinMachine system. Bulletin of Kazan Technological University 2011; 19: 193-198. Russian

29. Nikolaev A, Sokol I. Module APM Base - effective work with databases. CAD and graphics 2005; 1: 4249.

30. Sokol I, Savchenko Y, Shanin D, Rosinsky S. Data Base "APM Data" - connecting element in structure APM WinMachine. CAD and graphics 2002; 9: 9-12.

31. OST 38 05114-76. Toothed belt transmissions. Calculation Methods.

32. Shevchenko SV, Mukhovaty OA, Krol OS. Toothed belt transmission. Patent of Ukraine 2015; 100880.

Received 2020-07-09

Accepted 2020-11-02

Available online 2020-11-09

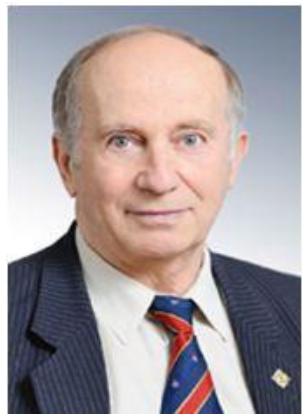

Oleg KROL (ORCID 00000003-0193-2750), PhD, Professor of the Machinery engineering and applied mechanics department of the Volodymyr Dahl East Ukrainian National University, Severodonetsk, Ukraine.

Main directions of scientific research: 3D- and parametrical modelling, machine tool design, $\mathrm{CAD} / \mathrm{CAM} / \mathrm{CAE}$ system, optimization in mechanical engineering, mechanical transmission reliability

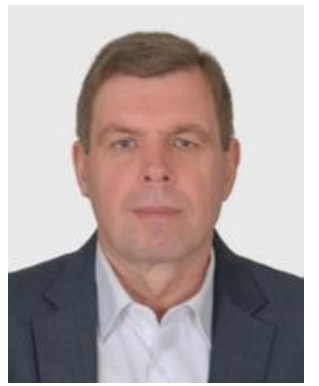

Volodymyr SOKOLOV (ORCID 0000-0003-04591824), Doctor of Sciences, Head of the Machinery engineering and applied mechanics department of the Volodymyr Dahl East Ukrainian National University, Severodonetsk, Ukraine.

Main directions of scientific research: automatic drives of technological equipment, dynamics and regulation of technological systems. 